\title{
Microbial Safety, Visual Quality and Consumers' Perception of Minimally- Processed Ready-to-eat Salad Vegetables Prepared and Stored at Room and Refrigeration Temperature
}

\author{
Md. Nazim Uddin', Sharmin Zaman², Ashfaq Aziz², Kazutaka Yamamoto³, Yohiko Nakaura ${ }^{3}$, and \\ Md. Latiful Bari² \\ ${ }^{I}$ Horticulture Research Division, Bangladesh Agriculture Research Institute, Gazipur-7205, Bangladesh; ${ }^{2}$ Center for Advanced Research in Sciences, University \\ of Dhaka, Dhaka-1000, Bangladesh; ${ }^{3}$ National Food Research Institute, Kannondai 2-1-12, Tsukuba-Shi, Ibaraki 38645, Japan.
}

\begin{abstract}
Raw salad vegetables are evaluated for the consumer's perceptions on taking ready to eat fresh cut-vegetables and the effectiveness of some non-chlorine disinfectants [peracetic acid (PAA), shell powder (SP) and hydrogen peroxide $\left(\mathrm{H}_{2} \mathrm{O}_{2}\right)$ ] in improving the microbial safety, quality and shelf life of ready to eat fresh-cut vegetables (lettuce, carrot and cucumber) at ambient and refrigeration temperature. Consumer's perception study results identified three clusters of consumers, whose preferences are related to purchasing styles and socio-demographic variables. The overall positive attitude of consumers was evident towards convenience, taste and appearance, but safety and health benefit attributes get importance while buying the ready to eat fresh-cut vegetables. The microbiological and visual observation result demonstrated that, all the non-chlorine sanitizers used were able to decrease the bacterial population in fresh-cut vegetables initially; however, microbial population increases or remain constant or decrease depending on the types of vegetables, storage temperature and duration. In addition, among the wash-sanitizers, PAA and $\mathrm{H}_{2} \mathrm{O}_{2}$ showed better microbial reduction for fresh-cut lettuce, and cucumber, and SP showed better microbial reduction for fresh-cut carrot. Irrespective of sanitizer treatment refrigerated storage showed better visual quality, microbial safety and shelf life of fresh-cut produce. Therefore, this study results suggested that washing fresh-cut vegetables with produce specific sanitizer and stored at refrigerated temperature keep the quality of fresh-cut produce better compared to ambient storage.
\end{abstract}

Keywords: fresh-cut vegetables; consumer's perceptions; Microbial safety; and storage temperature.

\section{Introduction}

Fresh-cut products are fruits or vegetables that have been trimmed, peeled and/or cut into an entirelyusable product, subsequently packaged to offer consumers high nutrition, convenienceand flavour while maintaining freshness ${ }^{1,2}$. According to Food and Drug Administration ${ }^{3}$, fresh-cut fruit and vegetable products are defined by being minimally processed (already washed,cut, mixed and packaged) and ready for consumption ${ }^{4}$.

The fresh-cut produce market in Asia has witnessed dramatic growth in recent years, primarily stimulated by consumer demand for fresh, healthy, convenient and additive-free foods which are safeand nutritious $5,6,7$. The market has shown a steady growth trend since the late 1980s and $1990 \mathrm{~s}^{8}$. Fresh-cut vegetables command a larger market share in Thailand ${ }^{9}$, $\operatorname{Japan}^{10}$, and Korea $^{11}$. With growing consumer demand for ready-to-eat products, the market for fresh-cut products in these countries is likely to show a continued growth trend. However, in South Asian countries, fresh-cut produce is sold in open-air markets and food stalls and is increasingly sold in supermarkets. Fresh-cut fruits, in particular, have gained popularity inurban centres and among young consumers. Often these products are displayed without the benefits ofrefrigeration, so their shelf-life is frequently not extended beyond the day of display.Fresh-cut vegetables for cooking constitute the most significant part of the fresh-cut produce industry. Fresh-cut salads are another major category as consumers perceive them to be healthy. However, with increasing demand for freshcuts at the retail level, the fresh-cut industry is facing challenges to extend shelf-life and enhance food safety $12,13,14$.

Since the preparation of traditional dishes also necessitates a variety of freshingredients in South Asia. The drudgery of peeling vegetables, shelling peas, trimming herbs and vegetables, and combining these ingredients often deters the busy housewife from preparing these traditional foods. Similarly, the difficulty of peeling fruits such as pineapple, jackfruits and watermelon and sometimes their large size deters the consumer from purchasing them. Fresh-cut processingaddresses all of these issues by making products available in a convenient, easy-to-use format withminimal waste ${ }^{15}$.Cottage industry suppliers are increasingly preparing packs of fresh-cut fruits and vegetables. They are being sold in wet markets in responseto consumer demand for produce in a ready-to-use format. 
Consumers generally purchase fresh-cut produce for convenience, freshness, nutrition, safety andthe eating experience. Indeed, consumer demand for these attributes has led to considerable innovation and diversification in the fresh-cut industry ${ }^{16}$. Apart from presenting the consumer witha range of options in a single package, freshcuts reduce wastage at the household level. They allow the consumer to procure only the quantities of fresh produce required. While fresh-cut produce requires relatively little product transformation, it requires investment in technology, equipment, management systems and strict observance of food safety principles and practices to ensure product quality ${ }^{17,18,19}$.

In Bangladesh, due to rapid urbanization, population growth, urban centres expansion occurred in the past two decades. At the same time, traditionalfood supply chains and food habits have been changing to keep up with these changing trends. These social changes include increases in single-person households, increases in middle-income populations; less time for meal preparation; increased demand for convenience food items; increased sales of ready-to-eat meals; and increases in the restaurant and fastfood operations ${ }^{20,21,22}$. Growth in the market opportunities for fresh-cut produce will continue only if consumers believethat fresh-cut produce is safe and of high quality with sufficient shelflife $^{23}$. Other challenges to themarketing of fresh-cut produce include: preserving product quality through the marketing chain; maintaining the cold chain and proper logistics; adequacy of processing equipment, refrigerated storage and processing facilities; availability of technology to set up processing plants and conduct research to preservethe quality of fresh-cut produce. Therefore, in this study,we evaluated the consumer's perceptions on taking ready to eat fresh-cutvegetables and the effectiveness of some non-chlorine disinfectants in improving the microbial safety quality and shelf life of prepared to eat fresh-cut vegetables at ambient and refrigeration temperature.

\section{Materials and methods}

\section{Consumer's perception study}

To understand the status of minimally processed ready-to-eat salad vegetables listing of the products have been done by visiting the five popular places for the street item, five salad bars and five chain shops (10 respondents of each and total 150 respondents). A short interview was taken to the stakeholders about processing environments, customer's behaviour, awareness about the safety and quality of minimally processed ready-to-eat salad vegetables etc. Three types of thequestionnaire were prepared; 1) consumers who take minimally processed fruit and/ vegetables from the street (Group A), 2) consumers of modern salad bars (Group B), and 3) consumers who purchased minimally processed ready-to-eat salad vegetables from the chain shop (Group C). The framework of the survey prepared (Fig 1) is extracted from a classic attitude-behaviour model based on Engel, Blackwell and Minland ${ }^{8}$. Attitudes are classified and called "search attitudes" (like freshness, color, and appearance), "experiences attitudes" (like taste and flavour) and "credence attitude" (like shelf life, health and microbiological safety). To gain insight into consumer decision making towards purchasing minimally processed vegetables and fruits cross-sectional data were collected through a consumer survey. Respondents were selected through non-probability judgmental sampling (population was selected based on personal judgment), and attribute data were as follows:

Perceived attribute importance in the purchasing (ImpPur) and consumption (ImpCon) stage of minimally processed fruits and vegetables; the average was produced on a scale from 1 (not at all-important) to 5 (very important). All form of data was collected and processed and analyzed.

\section{Microbial Safety and visual quality study}

Sample collection and processing: Fresh Carrots (Daucus carota L.), lettuce (Lactuca sativa var. capitata L.) and Cucumber (Cucumis sativa) were purchased from a local kitchen market (Gazipur, Bangladesh) and were transported to the laboratory within $30 \mathrm{~min}$ and upon arrival, they were manually processed. These three vegetables were included because of their initial microbial load, different topology of the vegetabletissue and their economic relevance in the fresh-cut produce industry. The carrots and cucumber were briefly peeled and pieces using a sharp Knife (DORCO, Korea). The outer leaves of lettuce were manually removed and cut into $1 \mathrm{~cm}$ pieces by a sharp knife. After cutting, each batch of vegetables was washed with each sanitizer (Distilled water, $150 \mathrm{ppm}$ PAA, $200 \mathrm{ppm} \mathrm{Cl}$ water, and $0.5 \% \mathrm{H}_{2} \mathrm{O}_{2}$ ) and air-dried for 2 hours. After drying, one batch undergoes microbial analysis and two batches of each were kept for storage study. A detailed illustration of washing procedures is given in Figure 2.

\section{Preparation of solution and washing}

The PAA solution was prepared following the methods of Vandekinderen et $a l .{ }^{24}$, with little modification. Initially the sample was diluted in a solution $(50 / 50, \mathrm{v} / \mathrm{v})$ of potassium iodide (10 g/L, Merck, Germany) and methanol (Merck, Germany) at $10^{\circ} \mathrm{C}$. The liberated iodine was titrated with a standardized 0.01 $\mathrm{N}$ sodium thiosulfate solution (Merck, Germany), and appropriate dilutions based on the active PAA concentration were made. The PAA concentrations were determined after optimizing the efficiency of varying PAA concentrations $(0,50,100$, and 150 $\mathrm{ppm}$ ) with fixed contact time (5 minutes) to remove the native microflora in three fresh-cut vegetables. The contact times were chosen after a screening of the relevant literature and taking into account practical considerations. $\mathrm{H}_{2} \mathrm{O}_{2}(0.5 \%)$ solution was prepared by adding deionized water (DW) to commercial $30 \%$ $\mathrm{H}_{2} \mathrm{O}_{2}$ and to prepare $0.1 \%$ SP solution, $0.1 \mathrm{~g}$ SP powder in 100 $\mathrm{ml}$ of DW was added. The utensils used (cutting board, knife, stainless steel tray, perforated trays etc.) in this Study, were dipped in $200 \mathrm{ppm} \mathrm{NaOCl}$ solution for 2 minutes. Afterwards, the materials were turned upside down for another $2 \mathrm{~min}$, and utensils were cleaned with $200 \mathrm{ppm} \mathrm{NaOCl}$ manually in the last minute. The working surface was sterilized by being sprayed with $70 \%$ 
ethanol (EtOH). The detailed activities from samples collection, processing of the vegetables up to microbial enumerations were given in Figure 3.

\section{Statistical Analysis}

All trials were replicated three times. Reported plate counts observed in all agar media were converted into colony forming unit $(\mathrm{CFU}) / \mathrm{g}$. The numbers represent the mean values obtained from three individual trials, with each of these values obtained from duplicated samples. Data were subjected to analysis of variance using the Microsoft Excel program (Redmond, Washington, DC, USA). Significant differences in plate count data were established by the least significant difference at the $5 \%$ significance level.

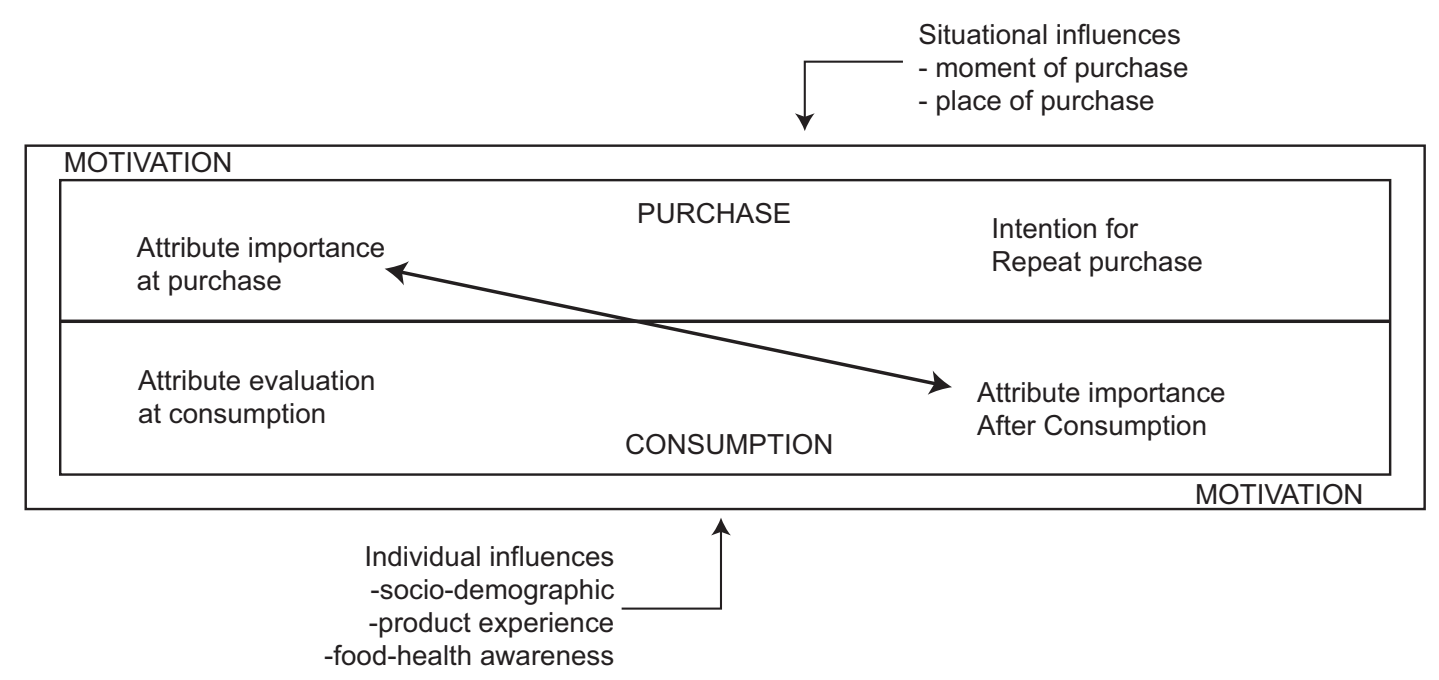

Fig 1: Framework and specific objectives (arrows) of the Study.

Materials and Methods of Vegetables Washing

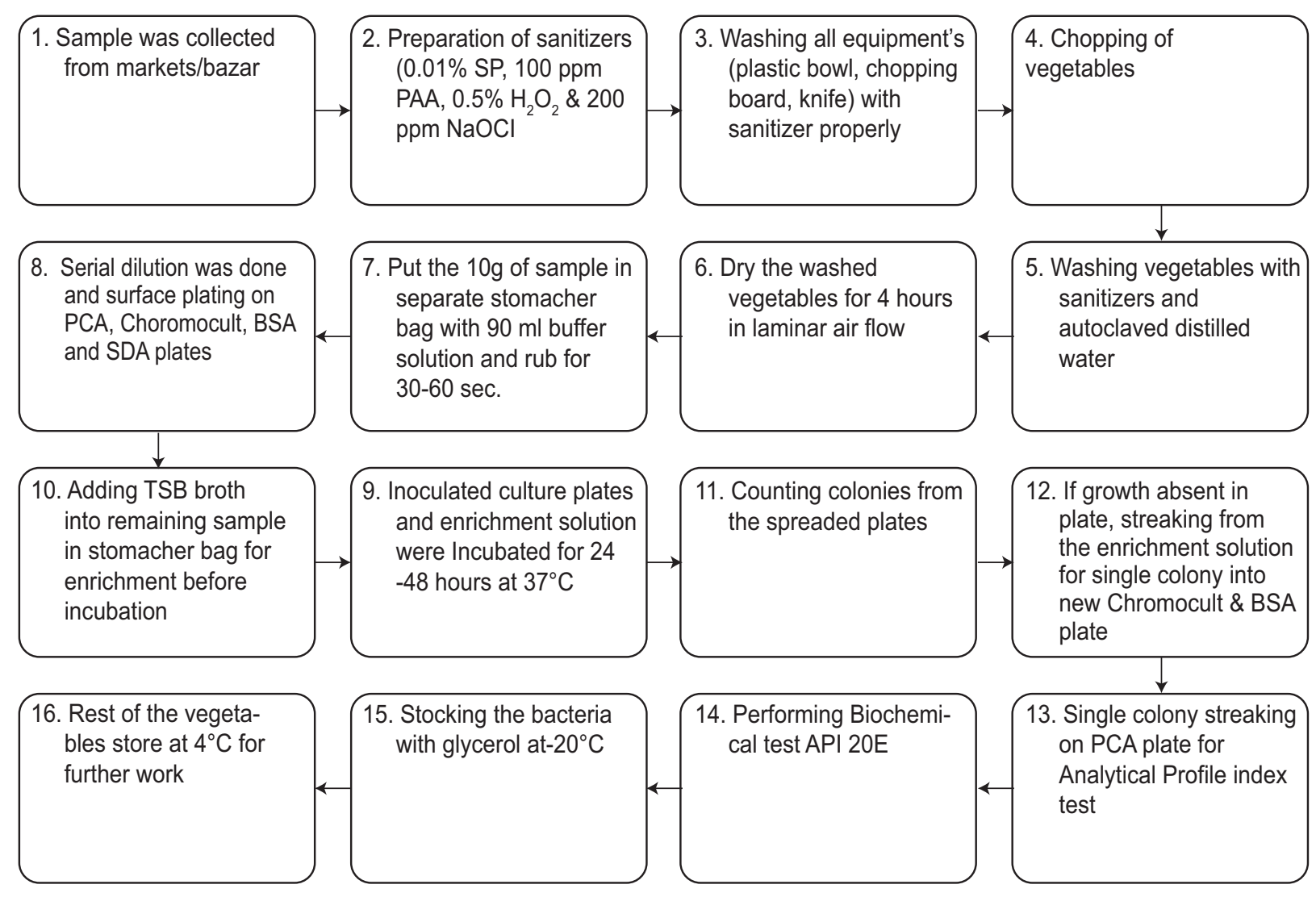

Fig. 2. Summary of the washing procedures and methods. 

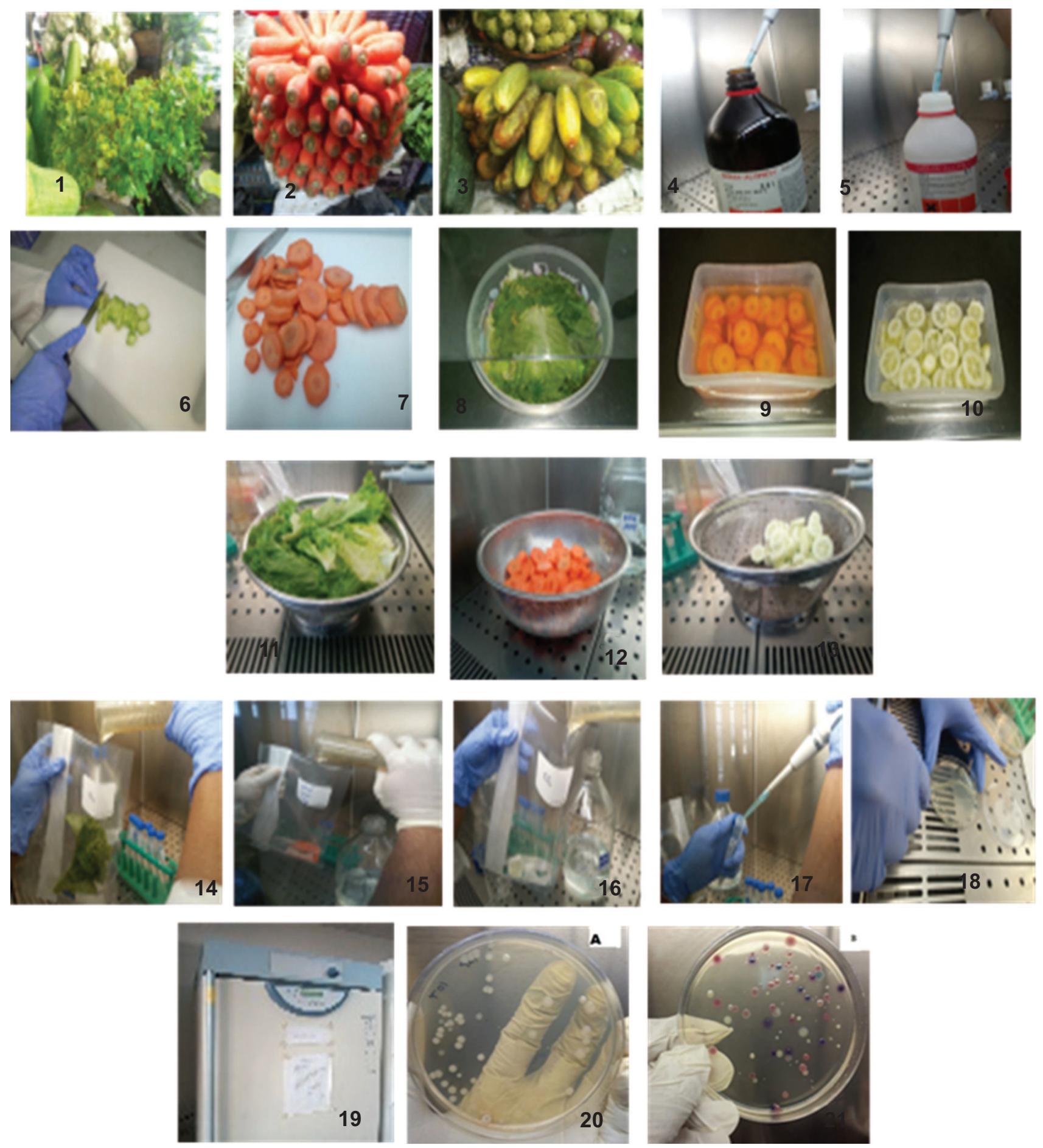

Fig. 3. Detailed activities from samples collection, processing of the vegetables including microbial enumerations 1 . Lettuce 2. Carrots, \& 3. Cucumber, 4-5. Sanitizer preparation, 6-7, chopping of vegetables, 8-10. Lettuce, cucumber and carrot washing 11-13. Drying after treatments, 14-16. Stomaching of samples 17. Serial dilution, 18. Plating 19. Incubation at 37R"C 20-21. enumerations.

\section{Results}

\section{Consumer's perception study}

In Bangladesh various types of consumers who take minimally processed ready to eat fruit and vegetables. However, three categories of consumers dominate or cover the maximum of the population. These consumers take processed fruits and vegetables at the street, at the modern salad bar, and buy from chain shops. This Study collected data from total 150 respondents, and the information was compiled and illustrated a fig 4 (A-D). The results demonstrated that the consumer who consumesstreet vendor's minimally processed fruits and vegetables gave importance in taste, odor, and appearance equally during purchase and consumption while giving safety the maximum importance during 
consumption (Fig 4A). The salad bar consumers preferred safety, health benefit, nutritional value, odor, shelf life, and taste in deciding on purchase and consumption. But during the purchase, they emphasizewashing (Fig 4 B). The chain shop consumers gave equal importance on all attributes during purchase but less on packaging (Fig 4 C). Invariably,safety and health benefit got the highest priority (Fig 4 D).

\section{Optimization of PAA concentration}

The influence of varying PAA concentrations $(0,50,100$, and $150 \mathrm{ppm}$ ) with fixed contact time (5 minutes) to remove the native microflora was tested in three types of fresh-cut vegetables:freshcut cucumber, carrots, and iceberg lettuce. It was observed that the efficiency of PAA to remove the native flora was highlydependent on the type of fresh-cut produce: the highest microbial reductions were obtained forcucumber (0.9-2.7 log $\mathrm{cfu} / \mathrm{g})$ and carrot (0.6-1.8 log cfu/g) followed by iceberg lettuce (0.3-0.8 log cfu/g) (Table 2). All the treated samples, regardless of the type of vegetable and concentration of the PAA treatment,
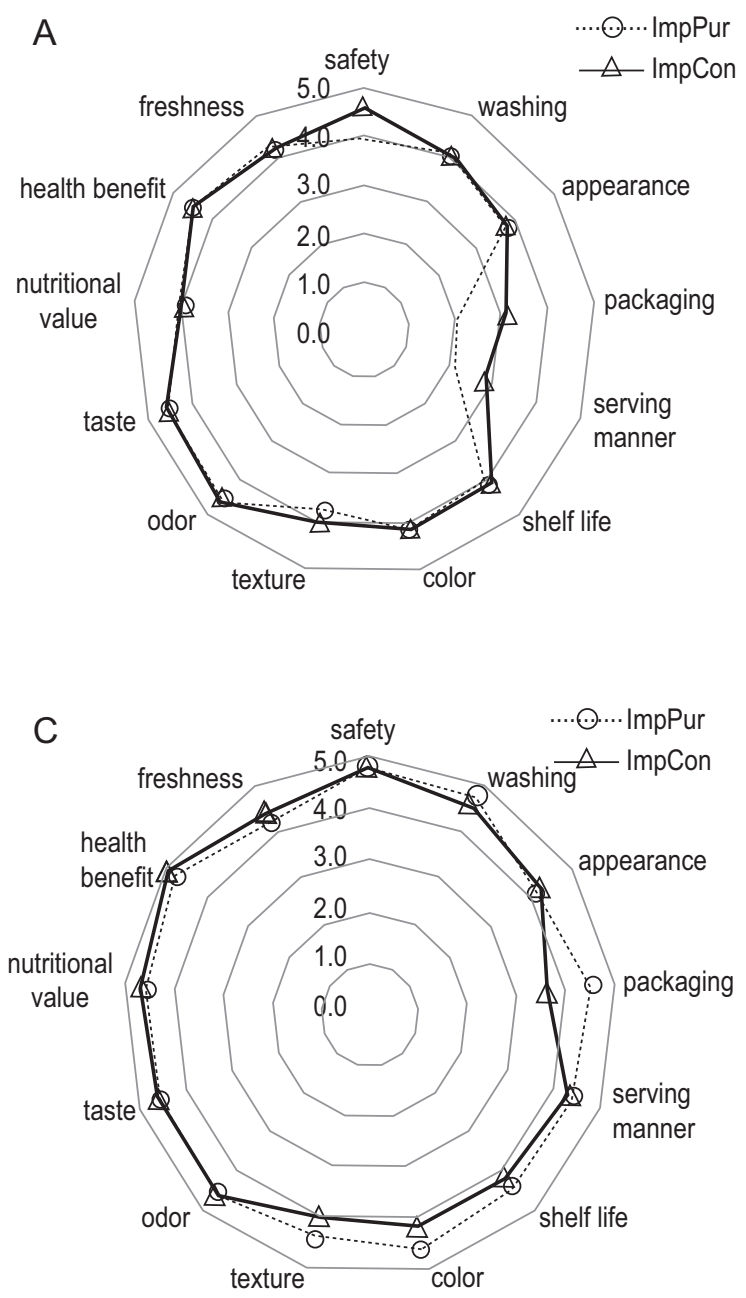

were within the recommended concentrations of common disinfectants and acceptable for consumption (Table 1). Furthermore, it was also observed that raising the concentration of PAA, increase the reduction efficiency of the bacterial count, but the effect was not persisted during both the room temperature and $4^{\circ} \mathrm{C}$ refrigeration storage condition, the microbial count increased significantly and reached to maximum permissible level for fresh-cut carrot (Fig 5). Based on these results, $150 \mathrm{ppm}$ of PAA was used in all the subsequent studies.

\section{Microbial Safety and visual quality study}

Lettuce: As lettuce is a highly perishable vegetable thus 6 days of storage in refrigerated $\left(4^{\circ} \mathrm{C}\right)$ and room temperature were evaluated after washing with each of the sanitizer or its combinations. The fresh cut lettuce samples were found relatively better in microbiological quality \& safety. The total aerobic bacterial count (TABC) count was recorded as $4.8 \log \mathrm{CFU} / \mathrm{g}$, TCC count was found present but non-detectable, E. coli was absent but the presence of fecal coliform was evident and recorded
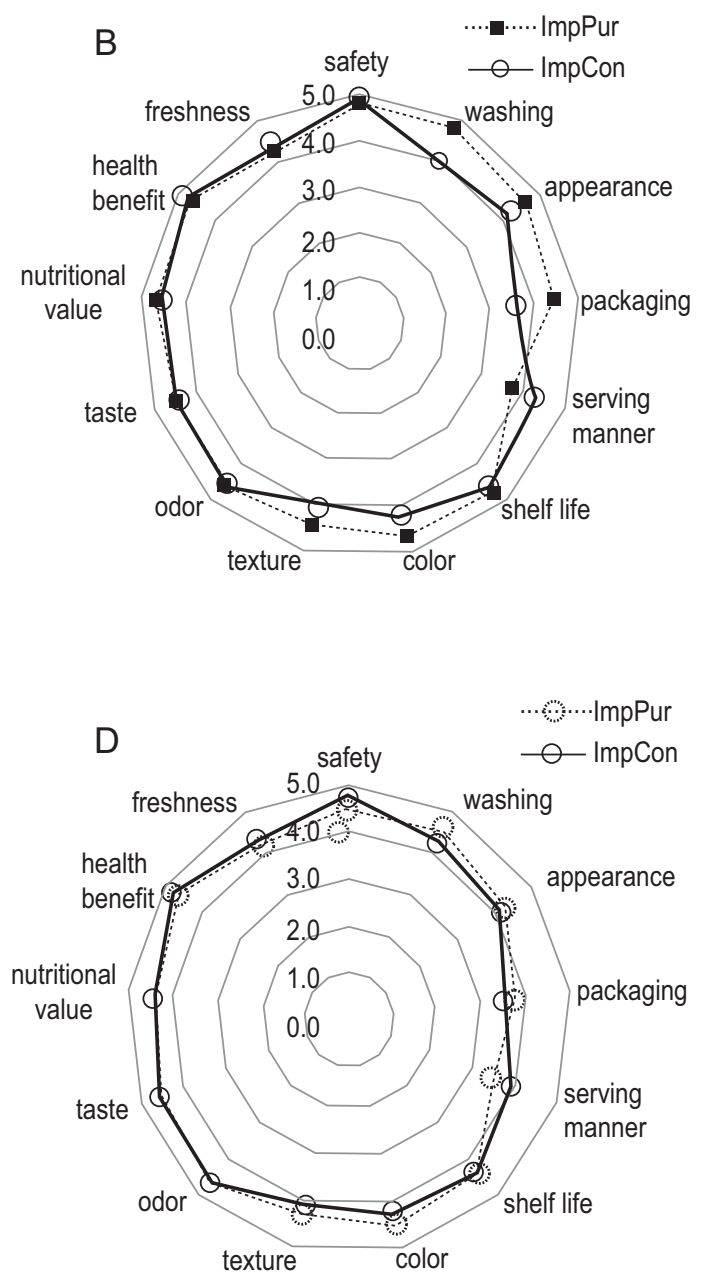

Fig. 4. Perception on minimally processed fruits and vegetables; street (A), modern salad bar (B), chain shop (C), average of all (D) of modern chain shop consumers (dot line possess ImPur=important during purchase, black line ImCon=Important during consumption (scale 1-5, 10 respondents from each group). 
Uddin et al.

Table 1: The recommended concentrations of common disinfectants (Huss 2003)

\begin{tabular}{lcc}
\hline Sanitizers & Food contact surfaces & Non-food contact surfaces \\
\hline Chlorine (ppm) & $100-200^{*}$ & 400 \\
Quats $(\mathrm{ppm})$ & $200^{*}$ & $400-800$ \\
Peroxyacetic acid (ppm) & $200-315^{*}$ & $200-315$ \\
\hline
\end{tabular}

The higher end of the listed range indicates the maximum concentration permitted without a required rinse (surfaces must drain)

Table 2: Optimization of PAA concentration in washing ready to eat salad vegetables for 5 minutes contact time

\begin{tabular}{|c|c|c|c|c|c|c|c|c|c|c|c|c|}
\hline & \multicolumn{4}{|c|}{$\begin{array}{c}\text { Lettuce } \\
\text { PAA concentration in ppm }\end{array}$} & \multicolumn{4}{|c|}{$\begin{array}{c}\text { Cucumber } \\
\text { PAA concentration in ppm }\end{array}$} & \multicolumn{4}{|c|}{$\begin{array}{c}\text { Carrot } \\
\text { PAA concentration in ppm }\end{array}$} \\
\hline & Control & 50 & 100 & 150 & Control & 50 & 100 & 150 & Control & 50 & 100 & 150 \\
\hline TABC & $4.4 \pm 0.5$ & $4.1 \pm 0.7$ & $3.8 \pm 0.3$ & $3.6 \pm 0.1$ & $4.8 \pm 0.0$ & $3.9 \pm 0.1$ & $3.8 \pm 0.0$ & $2.1 \pm 0.6$ & $3.9 \pm 0.0$ & $3.3 \pm 0.0$ & $2.9 \pm 0.4$ & $2.1 \pm 0.2$ \\
\hline TCC & $4.0 \pm 0.8$ & $3.0 \pm 0.4$ & 0 & 0 & $3.1 \pm 0.1$ & $2.8 \pm 0.1$ & $2.5 \pm 0.2$ & $2.3 \pm 0.7$ & $4.0 \pm 0.8$ & $2.9 \pm 0.0$ & $1.8 \pm 0.0$ & 0 \\
\hline E. coli & 0 & 0 & 0 & 0 & 0 & 0 & 0 & 0 & 0 & 0 & 0 & 0 \\
\hline Salmonella spp & 0 & 0 & 0 & 0 & 0 & 0 & 0 & 0 & 0 & 0 & 0 & 0 \\
\hline TFC & $4.2 \pm 0.0$ & $3.5 \pm 0.2$ & $3.3 \pm 0.8$ & $3.3 \pm 0.6$ & $4.4 \pm 0.8$ & $2.5 \pm 0.2$ & 0 & 0 & $4.2 \pm 0.8$ & $3.1 \pm 0.0$ & $2.3 \pm 0.1$ & 0 \\
\hline
\end{tabular}

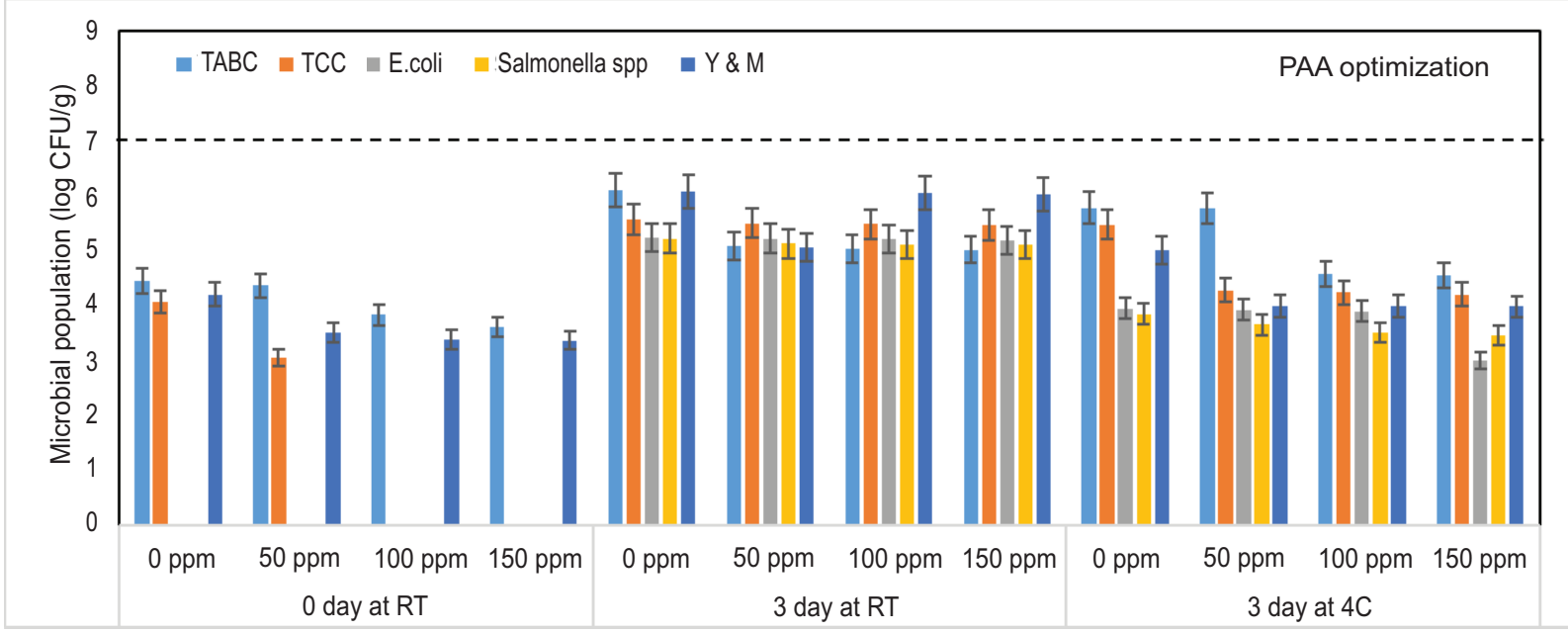

Fig. 5. Efficiency of PAA concentration during 3 days of storage fresh cut carrots at ambient and refrigeration temperature (4 ${ }^{\circ}$ C).

as $3.3 \log \mathrm{CFU} / \mathrm{g}, \mathrm{Y}$ and $\mathrm{M}$ count was recorded as $3.75 \mathrm{CFU} / \mathrm{g}$ (Fig 6 A). Washing lettuce with distilled water was found unable to reduce the bacteria and Y \& M. On the other hand, SP water wash reduces the TABC by approximately $1.0 \mathrm{log} \mathrm{CFU} / \mathrm{g}$, but failed to reduce yeast and mould count. $\mathrm{H}_{2} \mathrm{O}_{2}$ wash was able to lower TABC about $2.0 \log \mathrm{CFU} / \mathrm{g}$ and $\mathrm{Y} \& \mathrm{M}$ count to an undetectable level. PAA wash was found most effective in reducing TABC count and Y\&M count to an undetectable level at Day 0.

When all this sanitiser-washed lettuce was stored at ambient temperature for three days and 6 days, the TABC, TCC, Salmonella spp.,and Y\&M count increased to an unacceptable level at day-3. He spoiled at day-6 in control and distilled water washed lettuce. Although SP waterwashed, $\mathrm{H}_{2} \mathrm{O}_{2}$ and PAA washed lettuce could retain acceptable microbiological criteria at day-3.
Still, all these values were either crossed or about to cross the permissible microbiological limit except $\mathrm{H}_{2} \mathrm{O}_{2}$ washed lettuce at day-6 (Fig 6 A).

In the case of refrigerated storage, little increase or decrease of TABC, total coliform count (TCC), Salmonella spp., and Y\&M count was observed in control and distilled water washed lettuce at Day-3 and Day-6. However, the microbiological counts of lettuce treated with various sanitizers were far below the acceptable microbiological limit up to 6 days of storage at refrigeration temperature. This finding suggested that washing the vegetables with sanitizers and stored at refrigerated temperature up to 6 days keeps the quality of lettuce better than ambient storage (Fig 6 B).

Visual Quality of Lettuce: The visual observation of treated and non-treated lettuce stored at ambient and refrigerated 
temperature, results demonstrated that irrespective of washing treatment, ambient temperature stored lettuce changes its color from green to pale green, hence visually becomes non-attractive to the consumers. On the contrary, visual quality of refrigerated stored lettuce at day 3 and day 6 , was relatively better, but non- attractive, despite various sanitizer treatment was done (Fig 6 C). This finding and microbial quality data demonstrated that washing with sanitizer and stored in refrigerator retain its visual quality little better than that of ambient temperature stored lettuce.

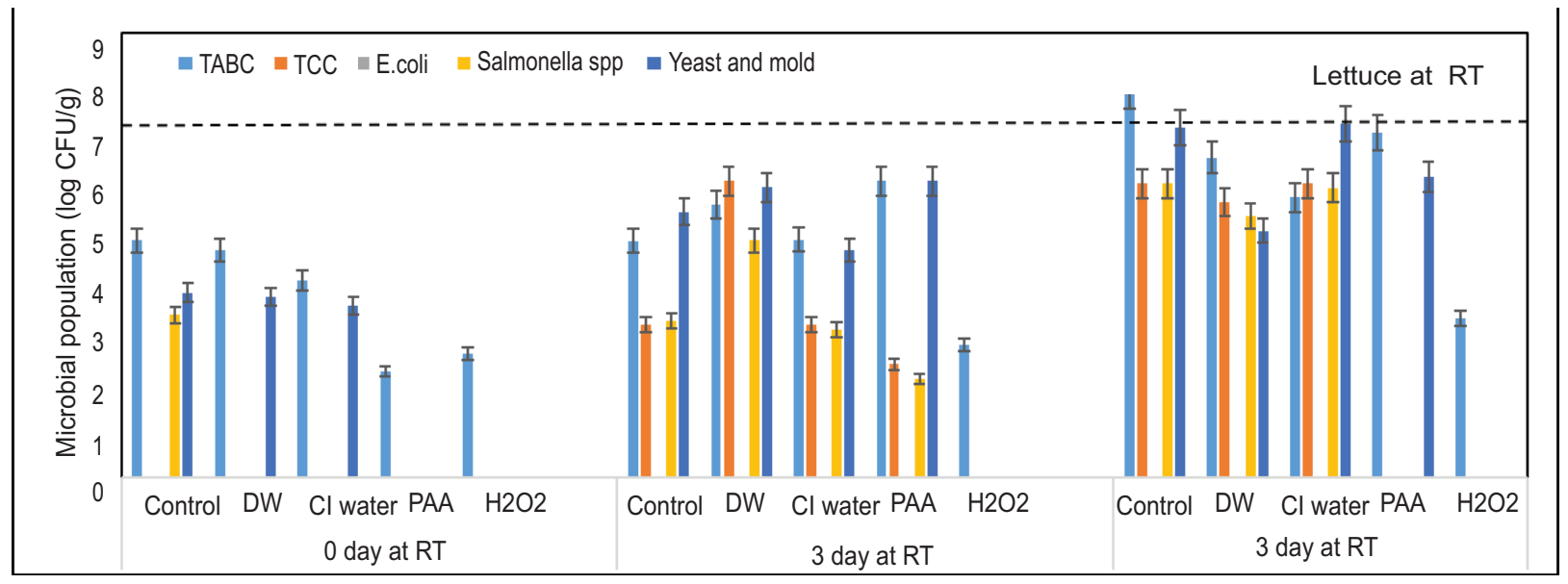

Fig. 6A. Microbial quality of various sanitizer-washed lettuces stored at ambient temperature up to 6-days.

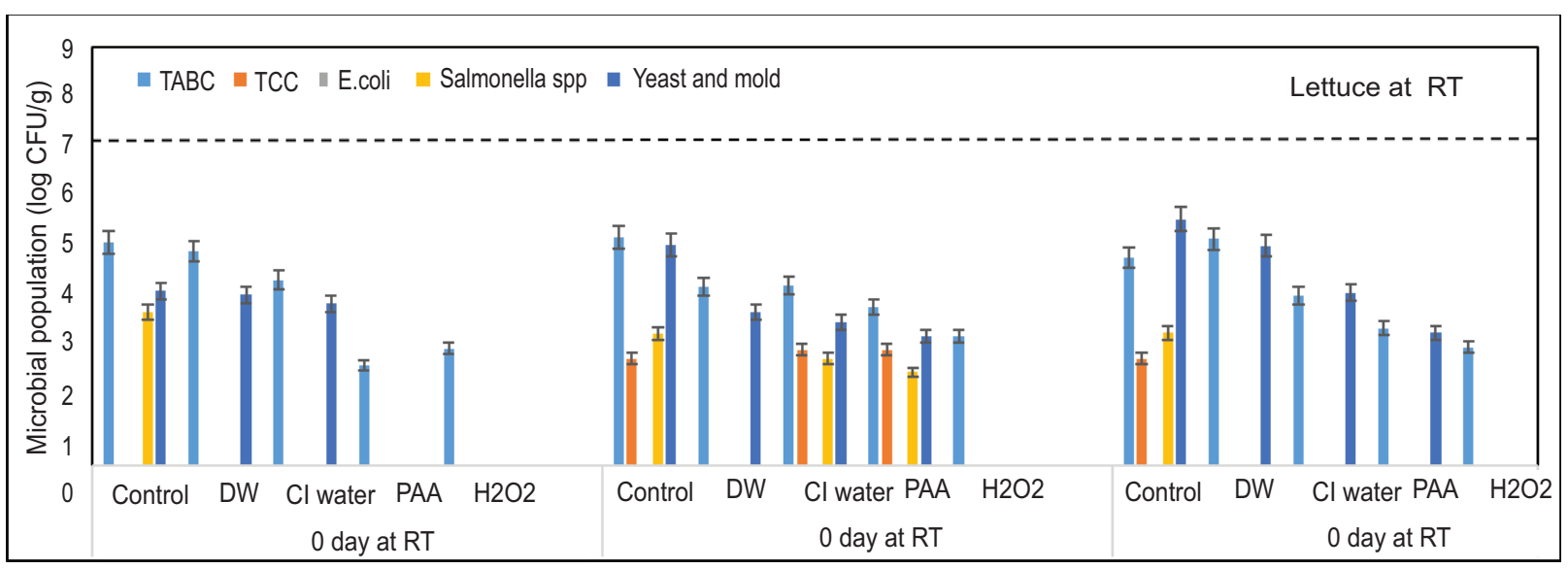

Fig. 6B. Microbial quality of various sanitizer-washed lettuces stored at refrigerated temperature up to 6-days.
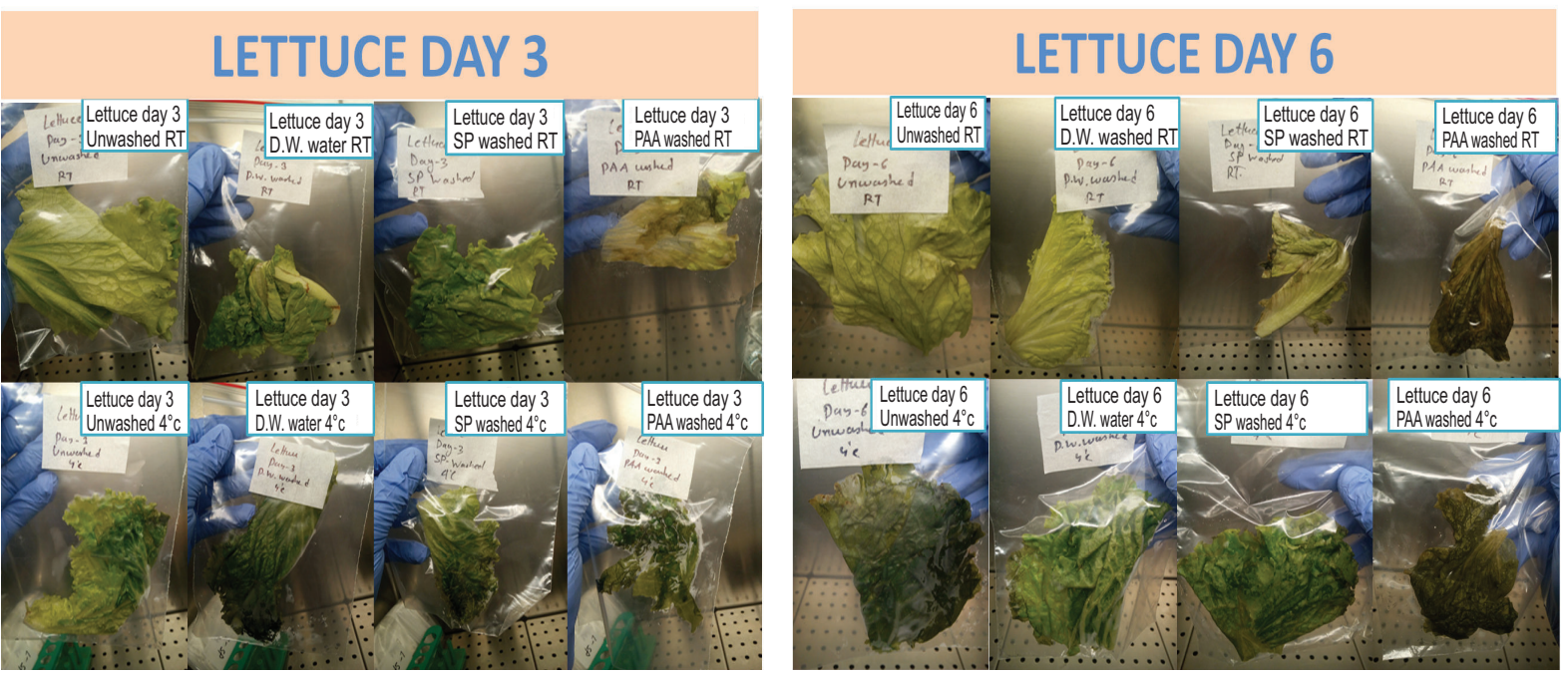

Fig. 6C. Visual quality of various sanitizer-washed lettuces stored at ambient and refrigerated temperature up to 6-days. 
Carrot: Carrot is a perishable vegetable but not as highly perishable like lettuce and cucumber thus extended storage of 13 days both at refrigerated $\left(4^{\circ} \mathrm{C}\right)$ and room temperature were evaluated after washing with each of the sanitizer. The total aerobic bacterial count (TABC) was recorded as $3.9 \log \mathrm{CFU} / \mathrm{g}$, total coliform bacteria was recorded as $4.08 \log \mathrm{CFU} / \mathrm{g}$, and yeast and mould count were recorded as $4.28 \log \mathrm{CFU} / \mathrm{g}$ (Fig $7 \mathrm{~A}$ ). Although no E. coli was found in the fresh-cut carrot samples, a higher presence (3.0 $\log$ CFU/g) of Salmonella spp was recorded in fresh-cut carrot samples. When fresh cut carrot was washed with sanitizers and stored at ambient temperature for 13-days, a gradual increase of TABC from 3.9 to $6.1 \log \mathrm{CFU} / \mathrm{g}$ at day 10 was observed and crossed the maximum permissible limit (7.0 $\log \mathrm{CFU} / \mathrm{g}$ ) at day 13. Among the wash sanitizers, $\mathrm{H}_{2} \mathrm{O}_{2}$ showed better reduction of TABC followed by PAA washed fresh-cut carrot. The lowest efficacy was observed for $0.1 \%$ SP water washed fresh-cut carrot stored at ambient temperature throughout the storage period (Fig $7 \mathrm{~A}$ ).

On the other hand, in the case of $4^{\circ} \mathrm{C}$ storage, irrespective of wash-sanitizer used, $\mathrm{H}_{2} \mathrm{O}_{2}$ washed fresh-cut carrot showed a better reduction in $\mathrm{TABC}$ and other microbiological counts to below detection level, compared to PAA and SP water and was able to retain the TABC count lower throughout 13-days storage at $4{ }^{\circ} \mathrm{C}$. The reduction of microbiological count was found in the following order $\mathrm{H}_{2} \mathrm{O}_{2}>$ PAA $>$ SP water $>$ DW wash (Fig 7 B).

Nonetheless, the microbiological counts of carrot treated with various sanitizers were far below the acceptable microbiological limit up to 13 days of storage at refrigeration temperature. This finding suggested that washing the vegetables with sanitizers and stored at refrigerated temperature up to 13 days keep the quality of fresh cut carrot better compared to ambient storage.

Visual Quality of Carrot: The visual observation of treated and non-treated fresh-cut carrot stored at ambient and refrigerated temperature results showed that irrespective of washing treatment, ambient temperature stored carrot did not change its colour and visual quality significantly, thus the visual quality was still attractive to the consumers throughout the storage period (Figure 7C). However, visual quality of freshness of fresh cut carrot was found relatively better in refrigerated stored samples, despite various sanitizer treatment was done. This finding along with microbial quality parameters data demonstrated that refrigerated stored fresh cut carrot was better than ambient temperature stored fresh cut carrot (Figure $7 \mathrm{C}$ ).

Cucumber: In this Study, cucumber is an intermediary perishable vegetable compared to carrot and lettuce thus, intermediary extension storage time ( 9 days) both at refrigerated $\left(4^{\circ} \mathrm{C}\right)$ and room temperature were evaluated after washing with each of the

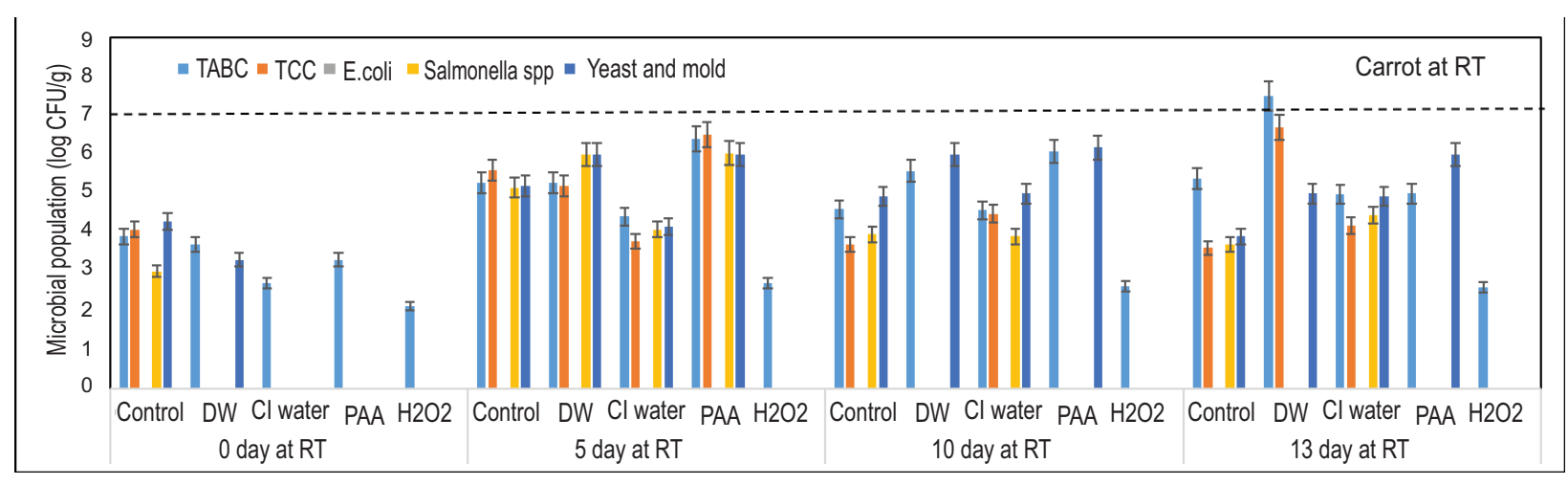

Fig. 7A. Microbial quality of various sanitizer-washed Carrot stored at ambient temperature up to 13-days.

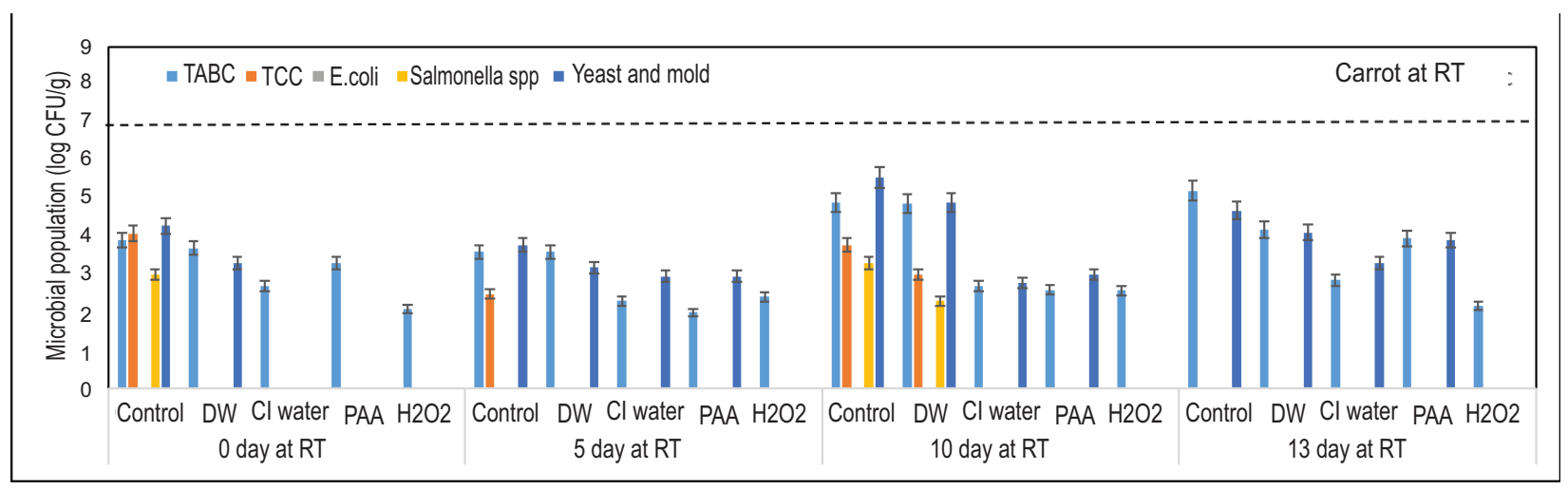

Fig. 7B. Microbial quality of various sanitizer-washed carrot stored at refrigerated temperature up to 13-days. 

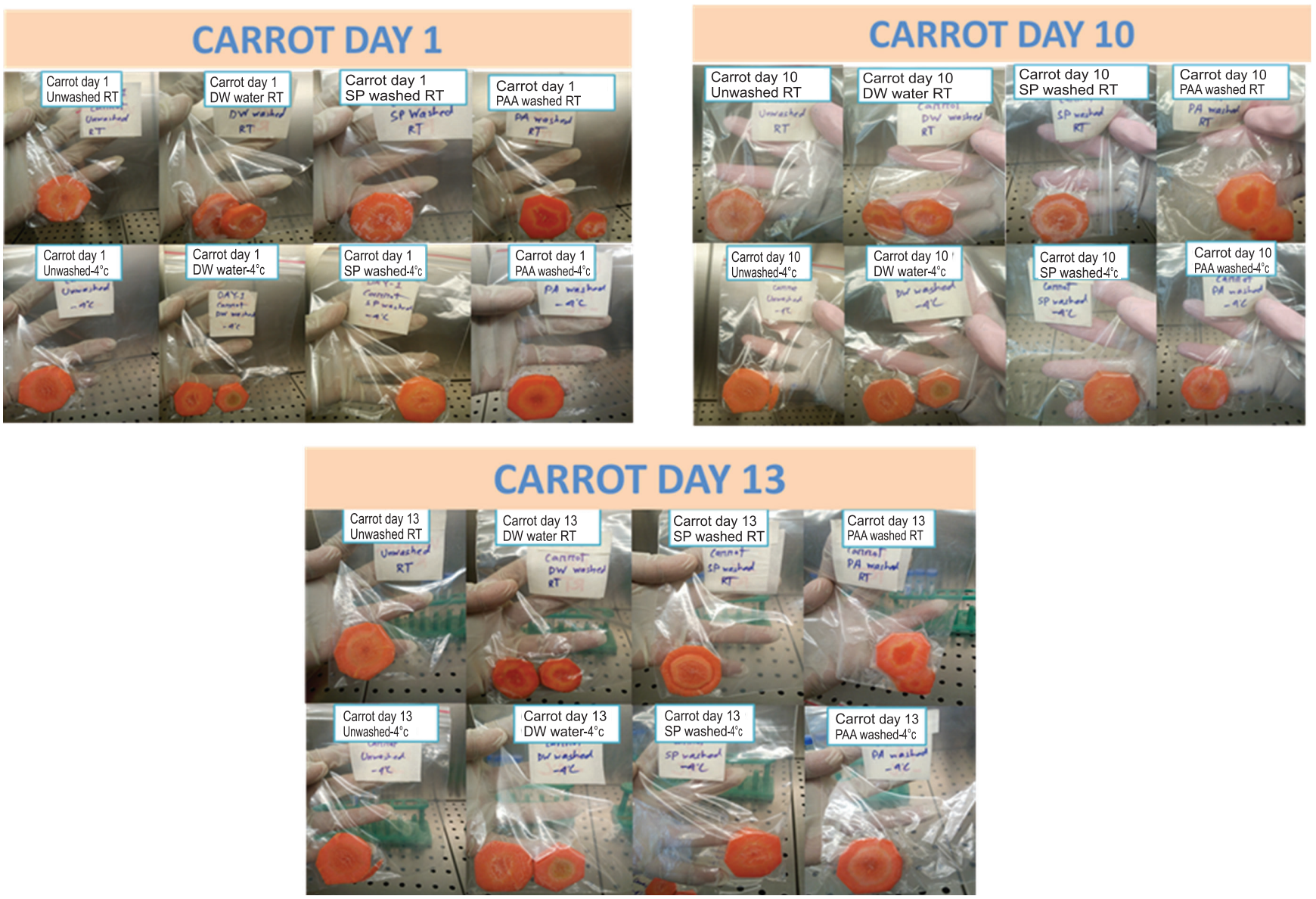

Fig. 7C. Visual quality of various sanitizer-washed carrot stored at ambient and refrigerated temperature up to 13-days.

sanitizer.The initial microbial load in fresh-cut cucumber was recorded as, $4.88 \log \mathrm{CFU} / \mathrm{g}$, total coliform count was recorded as $3.0 \log \mathrm{CFU} / \mathrm{g}$, yeast and mould count was recorded as, 4.48 $\log \mathrm{CFU} / \mathrm{g}$. Although the presence of E. coli was not evident throughout the Study, the presence of Salmonella spp was recorded as $2.4 \log \mathrm{CFU} / \mathrm{g}$ (Fig $8 \mathrm{~A}$ ). In the case of ambient storage fresh cut cucumber, washing with sanitizer was able to reduce the microbial load at 0 -day. However, a gradual increase was recorded at day- 3 and crossed the maximum permissible limit from day- 6 up to storage. $\mathrm{H}_{2} \mathrm{O}_{2}$ showed better reduction and retained the microbial load lower compared to other sanitizer used in this study throughout the storage period.

In the case of $4{ }^{\circ} \mathrm{C}$ storage, the situation was slightly better than the ambient temperature storage. When fresh cut cucumber was washed with $\mathrm{H}_{2} \mathrm{O}_{2}$ and stored at $40^{\circ} \mathrm{C}$ for 3,5 and 9 days, consistent retention of the microbial count was observed on days 3,6 , and 9. On the other hand, a slightly increase of the microbial count was observed with distilled water wash, PAA, and SP wash fresh cut cucumber, indicating that the fresh-cut vegetables should

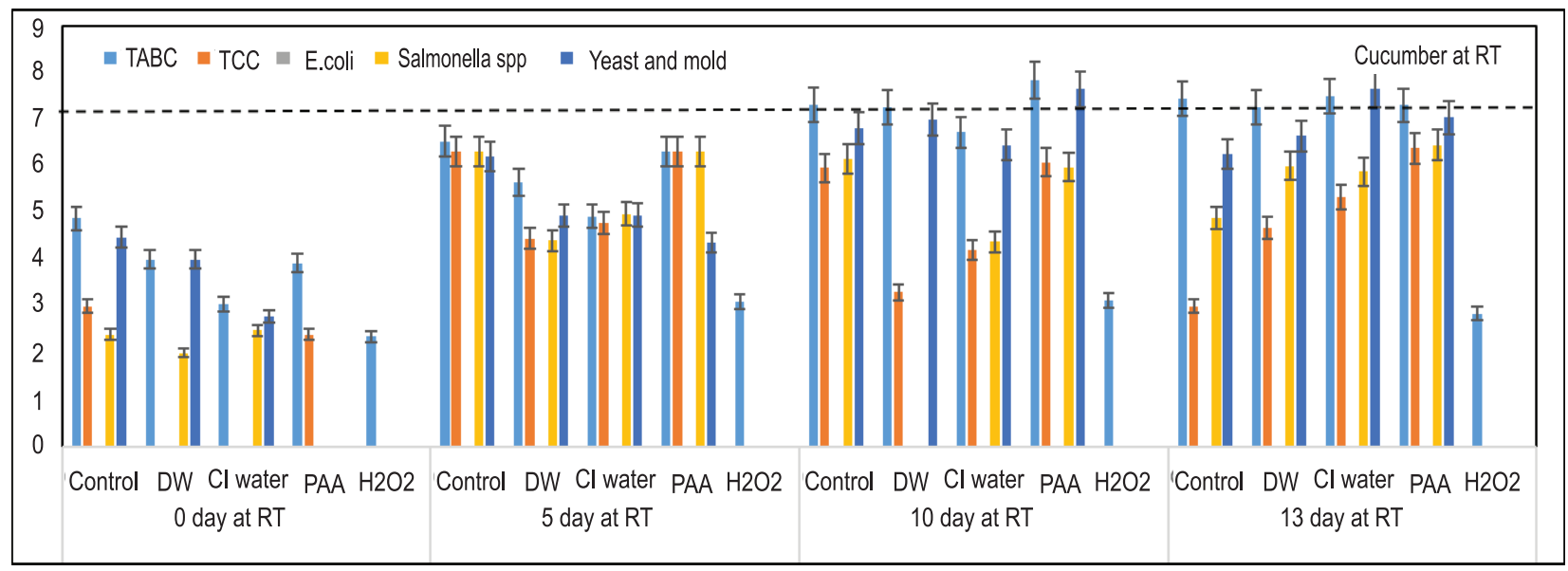

Fig. 8A. Microbial quality of various sanitizer-washed cucumbers stored at ambient temperature up to 9-days. 


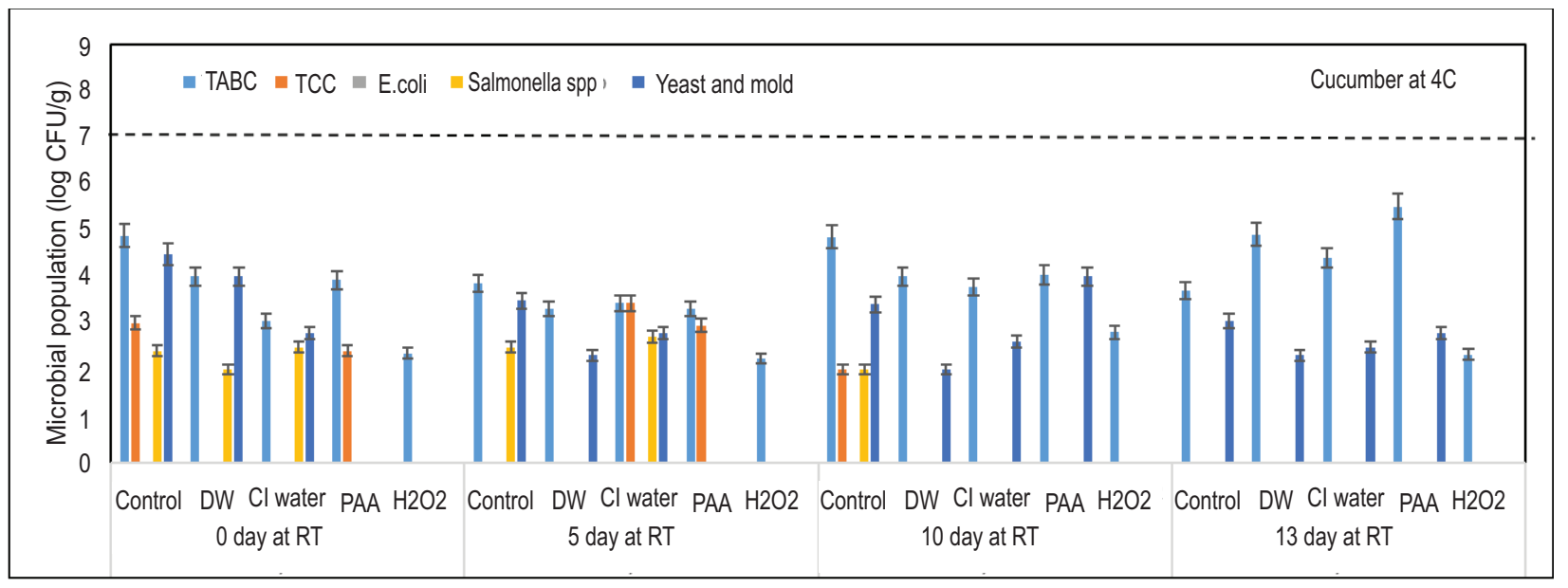

Fig. 8B. Microbial quality of various sanitizer-washed cucumbers stored at refrigerated temperature up to 9-days.
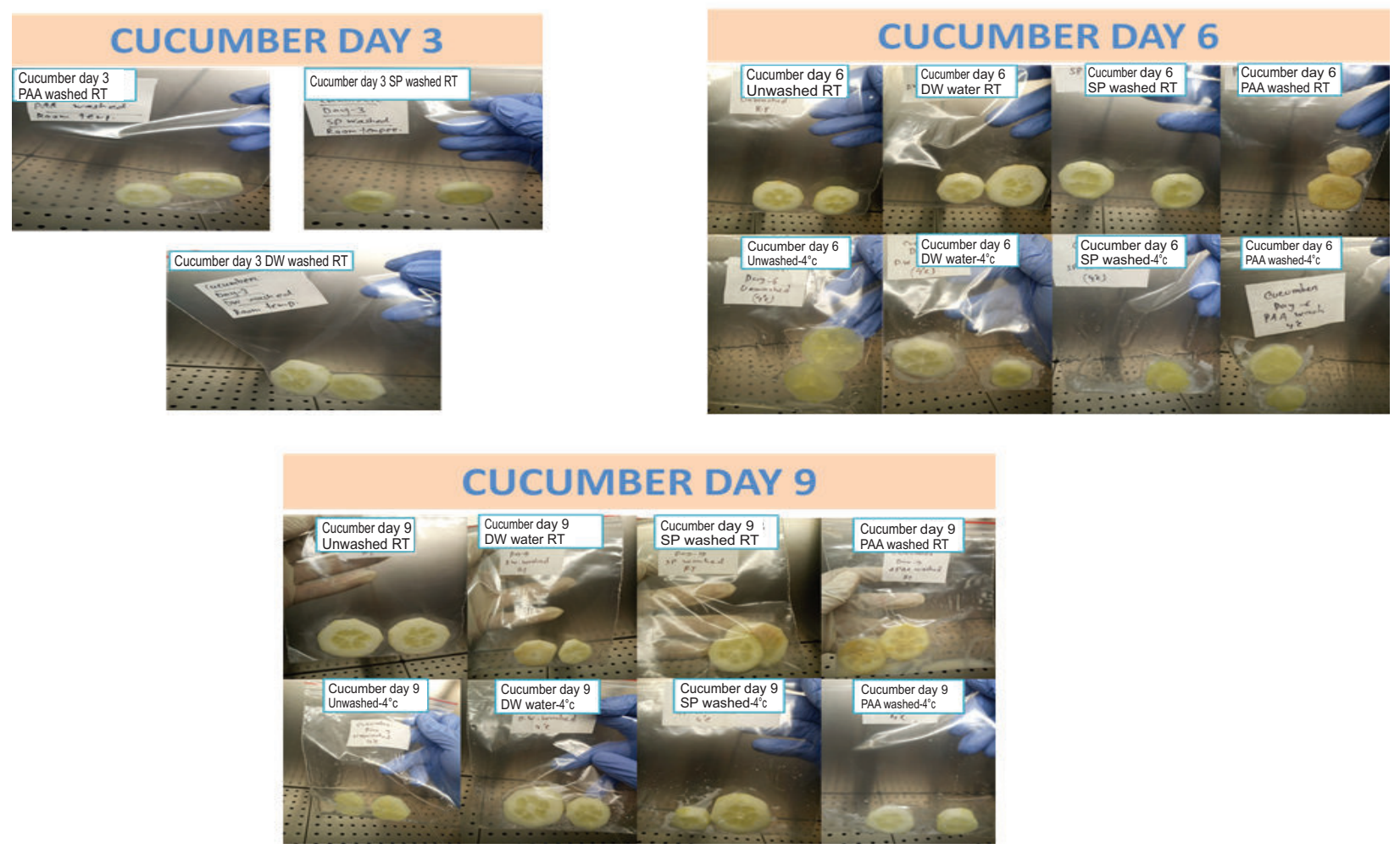

Fig. 8C. Visual quality of various sanitizer-washed cucumbers stored at ambient and refrigerated temperature up to 9-days.

keep at refrigerated temperature for better microbial quality and safety (Fig 8 B). However, compared to ambient temperature storage, the microbiological quality parameters of fresh cut cucumber treated with various sanitizers were still below the acceptable microbiological limit up to 9 days of storage at refrigeration temperature.

Visual Quality of Cucumber: The visual observation of treated and non-treated cucumber stored at ambient and ambient temperature results showed that irrespective of treatment condition, ambient temperature stored cucumber changes its texture from hard to soft with storage duration and on day-9 freshcut cucumber is softest and thus the visual quality becomes nonattractive to the consumers. On the contrary, visual quality on the texture of fresh-cut cucumber was observed relatively betterin refrigerated stored samples, despite various sanitizer treatmentsbeing done. PAA washed fresh cut cucumber among the wash-sanitiser showed good texture and visual quality acceptable at day- 9 of $4^{\circ} \mathrm{C}$ storage (Fig $8 \mathrm{C}$ ). This finding and microbial parameters, demonstrated that refrigerated stored freshcut cucumber was better to close to adequate level than ambient temperature storage ucumber. 
The overall result indicates that all the sanitizers could decrease the bacterial populationin fresh-cut vegetables initially. However, with storage temperature and time, microbial population increases or remain constant or lower depending on the types of vegetables, storage temperature and duration. Since ambient temperature is the optimum temperature for most aerobic bacteria to proliferate due to the favorable conditions and presence of nutrition for bacteria to grow. On the contrary, at $4^{\circ} \mathrm{C}$ is not a favorable condition for most aerobic bacteria, and at $4^{\circ} \mathrm{C}$, microorganisms can survive but were unable to increase. Only psychotropic bacteria can grow, which render the vegetables spoil or rotten with time. Therefore, washing fresh-cut vegetables with nonchlorine sanitizers and stored at refrigerated temperatures for a short time could be the marketing strategy for ready-to-eat freshcut salad vegetables.

\section{Discussions}

The basic form of primary processing, often known as minimal processing, involves sorting, grading, cleaning, drying, shelling/ threshing, and packaging fresh agricultural products. Fresh-cut vegetables are examples of primary processed products, which don't require heavy machinery or investment, instead they needa basic facilities for cleaning and freezing. However, good processing practices and handlers' good hygiene practices areimperative for the safe production of ready to eat fresh-cut vegetables ${ }^{25,26}$. The use of secondary ingredients is almost nonexistent in primary processing. In this study, after receiving the primary ingredients (lettuce, carrot, and cucumber), the ingredients were first sorted/trimming. For lettuce, the outer leaves were removed; for carrot and cucumber, dirt and debris were removed, then washed with tap water followed by distilled water, and peeled and then cut into small pieces. At this stage, microbial count was done. The results showed a higher number of Salmonella spp. in all the primary vegetables purchased, indicating that the receiving ingredients did not meet the quality standards and should be rejected. However, for the sake of the experiment we have accepted this primary ingredient to evaluate the effectiveness of non-chlorine sanitizers in eliminating pathogens and improving the shelf life at ambient and refrigeration temperature. SP, PAA and $\mathrm{H}_{2} \mathrm{O}_{2}$ washing successfully eliminated Salmonella spp. initially at ambient temperature, however, during storage, presence of Salmonella was evident in SP washed fresh cut lettuce at day 3 and day 6 ; and PAA washed fresh cut lettuce at day 3 but not at day-6; however, $\mathrm{H}_{2} \mathrm{O}_{2}$ washed fresh cut lettuce was seen eliminated Salmonella from day 0 up to day 6 at ambient temperature storage. Similar findings was observed in fresh cut lettuce stored at refrigerated temperature up to day 3 , however, at day 6 no Salmonella was observed, this might be due to the cumulative stress of cold temperature and the commensal microbial growth inhibited or inactivated Salmonella spp. or resident microbial growth may alter or spoil the food, or release secondary metabolites which inactivated or inhibited Salmonella spp. In addition, no Salmonella was detected even in DW washed fresh cut lettuce at day 6 under refrigerated storage support the causes of Salmonella inactivation. Furthermore, except in control lettuce, inhibition of Salmonella spp. in control carrot and cucumber samples at 13 days and nine days, respectively, was evident; this might be due to the disruption of the integrity of vegetables by slicing and peeling, thus facilitating enzymatic degradation on fresh-cut carrot and cucumber resulted in releasing some organic substances inhibitory to Salmonella spp., and lettuce may not have such enzyme to produce substancesinhibitory to Salmonella spp.

The shelf life of fresh produce depends on the initial microbial load, holding temperature and duration. In this study, total aerobic bacterial count (TABC) and total fungal count were considered as indicators of the shelf life of the fresh produce. Comparatively higher TABC load was recorded in lettuce and cucumber. Thus, holding this lettuce and cucumber at ambient temperature crossed the maximum permissible limit (7.0 log CFU/g) within six days of storage (Fig 6A and 8A). On the other hand, carrots contained a low initial microbial load and thus delayed in crossing the maximum permissible limit (Fig 7A). Nevertheless, irrespective of vegetables, none crossed the maximum permitted limit up to 13 days of storage at $4^{\circ} \mathrm{C}$.

Total coliform count indicates of processing places environmentin which the processing of the vegetables was done. Lower to moderate levels of total coliform bacteria were recorded in the vegetable samples. The presence of E.coli and Salmonella indicates faecal contamination at any stages along the value chain. Although no E. coli was observed, the presence of Salmonella was recorded showing the post-processing faecal contamination. Thus, pre-washing the vegetable with sanitizer is imperative for the safety of the fresh-cut produce.

\section{Conclusion}

The quality and safety of minimally-processed fruits and vegetables are essential parameters to get consumers' confidence in the fresh, minimally processed agriculture products. The overall result indicates that all the sanitizers could decrease the bacterial population in fresh-cut vegetables initially; however, with storage temperature and time, microbial population increases or remains constant or lower depending on the types of vegetables, storage temperature, and duration. Irrespective of sanitizer treatment, refrigerated storage showed better visual quality, microbial safety and shelf life of fresh-cut produce. Therefore, this study results suggested that washing fresh-cut vegetables with produce specific sanitizer and storingat refrigerated temperature keep the quality of fresh-cut produce better compared to ambient storage.

\section{Acknowledgment}

This study was supported by UNU-Kirin follow-up research Programin FY 2016-17 done at Bangladesh Agriculture Research Institute (BARI), Gazipur, Bangladesh.

\section{References}

1. Johnston CS and Gaas CA. Vinegar: medicinal uses and anti-glycemic effect. Med Gen Med, 2006;8:61. 
2. International Fresh-cut Produce Association. IFPA. 2000. "Fresh-cut Produce: Get the Facts!" www.fresh-cuts.org

3. FDA/CFSAN. 2007. Guide to minimize food safety hazards of fresh-cut fruits and vegetables. US Department of Health and Human Services.

4. Artes F and Allende A. Emerging Technologies for Food Processing. Elsevier; London, UK. Minimal fresh processing of vegetables, fruits and juices; 2005; pp. 677-716.

5. Blancou J. History of disinfection from early times until the end of the 18th century. Rev Sci Tech. 1995;14(21):39.

6. Slavin JL and Lloyd B. Health Benefits of Fruits and Vegetables. American Society for Nutrition Adv Nutr. 2012;3:506-516.

7. Steinmetz KA and Potter JD. Vegetables, fruit, and cancer prevention: a review. J Am Diet Assoc. 1996;96:1027-39.

8. Kim JG.. Fresh-cut market potential and challenges in Far-East Asia. Acta. Hort. 2007;746:53-60

9. Sanguanpuag K, Kanlayanarat S and Tanprasert K. Trends of fresh-cut produce in Thai retail markets for identification of packaging for shredded green papaya. Acta Horticulturae, 2007;746:481-483.

10. Yamamoto K. 2017. Food processing by high hydrostatic pressure, Biosci. Biotechnol. Biochem., http://dx.doi.org/10.1080/09168451.2017.1281723

11. Liu C, Hsu C and Hsu M. Improving the quality of fresh-cut pineapples with ascorbic acid/sucrose pretreatment and modified atmosphere packaging. Packag. Technol. Sci. 2007;20:337-343.

12. Garret EH. Fresh-cut produce: tracks and trends. In: Lamikanra O, editor. Fresh-cut fruits and vegetables: science, technology, and market. Boca Raton Fla. CRC. 2002; 21-9.

13. Russell AD. 1990. Bacterial Spores and Chemical Sporicidal Agents. Clinic Microb Rev. Apr. 1990, p. 99-119.

14. Stranieri S and Baldi L. Shelf Life Date Extension of Fresh-Cut Salad: A Consumer Perspective. J. Food Prod. Mark. 2017;23: 939-954. doi: 10.1080/10454446.2017.1266545.

15. Plazzotta S, Manzocco L and Nicoli MC. Fruit and vegetable waste management and the challenge of fresh-cut salad. Trends Food Sci. Technol. 2017;63:51-59. doi: 10.1016/j.tifs.2017.02.013.
16. Ragaert P, Verbeke, W, Devlieghere F and Debevere J. Consumer perception and choice of minimally processed vegetables and packaged fruits. Food Qual and Pref. 2004;15(3):259-270.

17. Abadias M, Usall J, Oliveira M, Alegre I and Vinas I. Efficacy of neutral electrolyzed water (NEW) for reducing microbial contamination on minimally-processed vegetables. Int J of Food Microb. 2008;123:151-158.

18. Baldry MGC. The bactericidal, fungicidal and sporicidal properties of hydrogen peroxide and peracetic acid. $J$ Appl Bacteriol. 1983;54:417-423.

19. Entani E, Asai M, Tsujihata S, Tsukamoto Y and Ohta M. Antibacterial action of vinegar against food-borne pathogenic bacteria including Escherichia coli O157:H7. J Food Prot. 1998;61:953-959.

20. Mahfuza I, Arzina H, Md. Kamruzzaman M, Afifa K, Md. Afzal H, Rashed $\mathrm{N}$ and Roksana $\mathrm{H}$. Microbial status of street vended fresh-cut fruits, salad vegetables and juices in Dhaka city of Bangladesh. Int Food Res J. 2016;23(5): 2258-2264.

21. Strawn LK and Danyluk MD. Fate of Escherichia coli O157:H7 and Salmonella on Fresh and Frozen Cut Pineapples. J Food Prot. 2010;418-424.

22. Vijaya kumar C and Wolf-Hall CE. Evaluation of household sanitizers for reducing levels of Escherichia coli on iceberg lettuce. J Food Prot. 2002; 65:1646-1650.

23. James JB, Ngarmsak T and Rolle RS. Processing of fresh-cut tropical fruits and vegetables. In: A technical guide, RAP PUBLICATION 2010/ 16; Food and Agriculture Organization of the United Nations, Regional Office for Asia and the Pacific Bangkok. 2011; 15-102.

24. Vandekinderen I, John VC, Frank D, Bruno De M, et al. Effect of Decontamination Agents on the Microbial Population, Sensorial Quality, and Nutrient Content of Grated Carrots (Daucus carota L.). J Agri and Food Chem. 2008;56(14):5723-31.

25. Calonico C, Delfino V, Pesavento G, Mundo M and Nostro AL. Microbiological Quality of Ready-to-eat Salads from Processing Plant to the Consumers. J Food Nutr Res. 2019;7:427-434.

26. de Oliveira MA, Maciel de Souza VM, Bergamini AMM and de Martinis ECP. Microbiological quality of ready-to-eat minimally processed vegetables consumed in Brazil. Food Cont. 2011;22(8):1400-1403. 